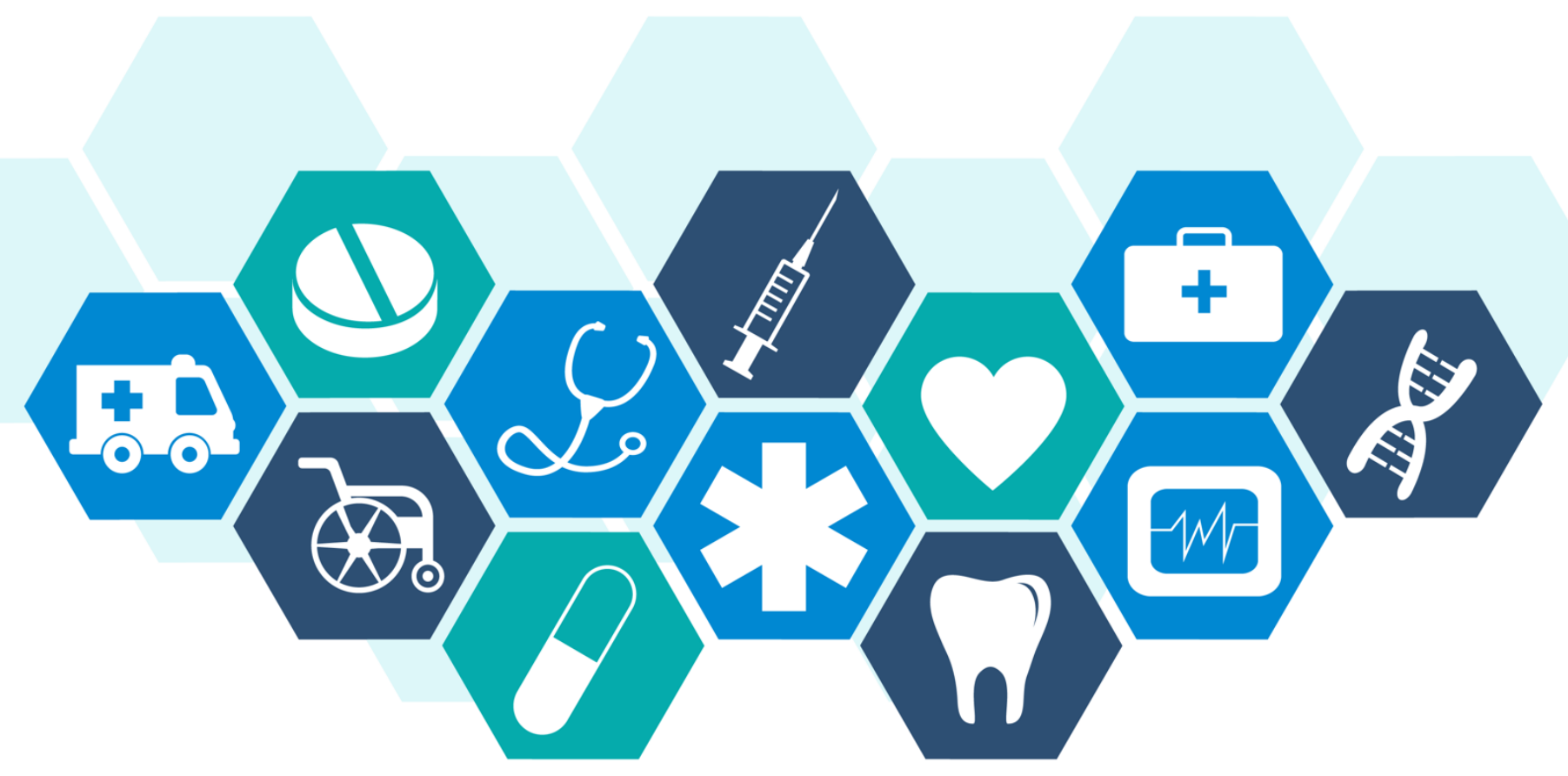

Editorial

\title{
Public Consultation: From Reflection to Action Quebec Health Politics and the Student Response
}

David Benrimoh, M.D.,C.M. ${ }^{1}$

MJM 2017 15(6)

Healthcare is perhaps the place where there is the most direct and intimate contact between the government and the people it serves. It is also a place where the inherent power imbalance between patients who need care and the institutions that provide that care can lead to tension, frustration, and injustice. Add to this the political dimensions, such as the fact that healthcare funding is the largest item in the provincial budget [1], and it is no surprise that debates around healthcare provision and financing are often polarizing. Many models exist and many panaceas have been proffered from privatization to personalization to computerization; but still, no government seems to have quite gotten it right. Even worse, the workings of the system are so obscure, the network of services offered so complex, and the interests of all the players (patients, doctors, federations, unions, suppliers) so hard to discern and reconcile, that the current Quebec
Minister for Health and Social Services, Gaétan Barrette, has said on camera that public consultation prior to reform would take 20 years. This was his justification for rolling through his recent reforms like a bulldozer (a nom de guerre he has said he appreciates).

Some may actually be comforted by this approach - the idea that one man with a vision can swoop in and clean things up. It's something we are accustomed to through similar tropes in popular media. And yet, at least from the health professional perspective, there is something that feels fundamentally wrong with this kind of action; the sense that something is sacrificed. There is perhaps nothing more disillusioning than having the system you work in, the system you fight for every day, being changed without your input or consent, and then being told that you must contort yourself to fit within its new confines.

\footnotetext{
${ }^{1}$ Psychiatry Residency Training Program, McGill University Department of Psychiatry, Montréal, Canada.

Corresponding Author: David Benrimoh, email david.benrimoh@mail.mcgill.ca.
} 
As a professional, it is frustrating to watch the system being adapted to political goals instead of to the people who work in it, and the people it serves.

Healthcare professionals today are moving away from the paternalism of the past and learning a new approach-patient partnership [2]. There is also a need to train future healthcare practitioners to be socially accountable [3]. These trends are essentially calling for the democratization of healthcare systems and the empowerment of those the system is supposed to serve: patients, their families, and the taxpayers who fund it all. While it is admittedly difficult to study and demonstrate concrete improvements in outcomes as a result of public participation in healthcare planning, we do know that such participation brings different perspectives to the table and can impact policy [4]. The perspectives of the people we serve as healthcare professionals are also invaluable for the improvement of our individual and collective practice. Further, working to address the concerns and suggestions of patients and their families also leads to a sense of citizenship and collective ownership of the system. This in turn leads to trust and good-will- the building block upon which the therapeutic alliance is built.

In addition to the public's voice, we must consider the voice of those who work in the system. These are overburdened nurses who have too many patients; hospital managers who have too many teams and sites to watch over; or family doctors with a dearth of time and an abundance of patients in the waiting room. Best practices in change management dictate that any reform needs to be developed with and communicated clearly to those in the workforce affected by it [5]. Shutting workers out of the change-making process deprives the top level of management of their goodwill, insight and expertise. Not cultivating worker engagement can contribute to the failure of changes in organizations [6].

Another key group affected by changes in the healthcare system are health professions students who are being forced to reimagine their future practice in light of Dr. Barrette's reforms. These reforms are proceeding counter to our training, which encourages a commitment to patient partnership and a sense of social accountability and professional identity. Compounding the problem, our voice seems comparatively small in a time when even our professors' voices are being ignored. In a way, many of us felt we weren't even on the map. This sense, coupled with our perception of the Minister's insistence on patient quotas as an attack on family medicine and patient partnership, is what led to the historic first strike by all four medical schools in Québec [10].

Emboldened by the way the strike united medical students, we searched for further avenues of advocacy, a way to keep the movement going beyond the strike. Several things were clear. First, healthcare professionals had a poor track record of collaboration with each other, not only in the clinic but also in the political sphere. This was true despite strong evidence for the benefits of interprofessional collaboration in primary care [7]. Second, we felt that the Minister's claim that consultations would take 20 years was an egregious exaggeration given that the CastonguayNepveu commission, which created the healthcare system, only had to hold public consultations for two years [8]. Lastly, we knew that as the healthcare professionals of the future, the ones who would have to inhabit the house Barrette built, we wanted a say in the reform.

To address these three concerns, students needed to organize themselves. The result was the FRESQue (FRESQue - Forum de la Relève Étudiante pour la Santé au Québec or the Quebec Health Professional Students' Roundtable), an organization bringing together all health professional students in the province for the first time. Our mandate is to analyze provincial healthcare system issues, create and provide recommendations to the government, and engage in advocating for our recommendations and for increased public participation in health policy creation. We wanted to ensure that health professions students will always have a voice in health policy. The intention was not to simply react to ongoing events, but to create an organization that would empower health professional students to work together proactively, discussing different topics every year and identifying priority areas in which to intervene. We wanted to prove that our ideas could be a useful part of healthcare policy debates. In addition, a special mandate of the FRESQue is public consultation, because we felt as professionals dedicated to patient care that it was important to ensure that patients and their families also had a voice. In effect, we set out and said, "If the government won't do public consultation, we'll do it for them."

\section{And we did.}

In six short months we gathered together our student associations, decided our inaugural theme 
would be "Improving Access to Primary Care", raised money, contacted patient groups, professional orders, and other stakeholders, and hosted a very successful summit on improving access to primary care. We chose access to primary care because this was both a very current topic at the time and a prime focus of the Minister's reforms. Before the summit, we received over 400 pages of memoranda detailing recommendations for improving primary care; this translated into 120 individual recommendations. These were sent to us by student associations, charities, experts, patients, and members of the general public. We wrote articles, we were interviewed, we spoke up, and we demanded that the government engage in public consultation. At the summit, we connected seasoned healthcare professionals with students, patients, and members of the general public. We heard from an expert on patient partnership, the opposition health critic, and from the Minister himself. After what felt like long hours of intense and fascinating debate, we voted on a list of recommendations that we showed to the Minister directly.

The results, which can be found at lefresque.com, are evidence-based recommendations for improving access to primary care. They include [9]:

- Recognizing the roles played by all health professionals and allowing them to exercise their full scope of practice.

- Ensuring that healthcare establishments are run by an interdisciplinary committee that includes patients; similarly, ensuring that patients can hold healthcare institutions accountable by sitting on the board of local institutions.

- Improving collaboration infrastructure between primary care professionals in different milieus, including community organizations and schools.

- Creating integrated primary care teams comprised of different kinds of professionals based on local assessments of needs.

- Shifting focus from treatment to prevention and public health measures, and ensuring a strong focus on education.

- Increasing the training opportunities for health professionals in underserved regions.

These are a few of our passed recommendations and a fraction of the total number of recommendations submitted to us. As such, we achieved both of our objectives: we analyzed a health policy issue and came up with useful recommendations for improving the current state of affairs, and we succeeded in carrying out a public consultation in a short amount of time.

But beyond media attention and the satisfaction that comes from proving a Minister wrong, what came of all this? What do we have to show for our efforts?

First and foremost, we have given a generation of future health professionals an alternative to cynicism and disengagement. We have provided a forum not just for action, but for the building of partnerships among professionals and patients. These partnerships and the conversations from which they arose were the highlight of the endeavour for many of our members. We provided an opportunity for the public to learn to trust that there are professionals who care about what they think. We have created that an organization that will endure and evolve beyond the mandate of this health minister and the next. In the process, we have proven that students can come together, produce useful ideas, raise their voices, and catch the attention of those in power.

We are at a crossroads for family medicine and for the provincial medical system itself. We made the choice as future professionals to engage with each other, with the public, and with the policy-making process. We made the choice to not only stand up for but to live for our ideals. And we will keep making that choice because it falls to us - the future - to work with the people we serve to defend and continually improve the system that serves us all.

\section{References}

1. The Québec Economic Plan - March 2016 [Internet]. Québec: Finances Québec; 2016 [cited Feb 17, 2017]. Available from http://www.budget.finances.gouv.qc.ca/budget/ 2016-2017/en/documents/EconomicPlan.pdf

2. Karazivan P, Dumez V, Flora L, Pomey M-P, Grande CD, Ghadiri DP, et al. The Patient-as-Partner Approach in Health Care. Academic Medicine. 2015;90(4):437-41.

3. CACMS Standards and Elements for Schools with Visits in 2017-2018 [Internet]. Ottawa: Committee on Accreditation of Canadian Medical Schools; 2016 [cited Feb 17, 2017]. Available from https://cacmscafmc.ca/sites/default/files/documents/CACMS_Stan dards_and_Elements_-_AY_2017-18.pdf

4. Mitton C, Smith N, Peacock S, Evoy B, Abelson J. Public participation in health care priority setting: $A$ scoping review. Health Policy. 2009;91(3):219-28.

5. Kotter JP. Leading Change: Why Transformation Efforts Fail . Harvard Business Review . 1995(MarchApril):1-9. 
6. Paper DJ, Rodger JA, Pendharkar PC. A BPR case study at Honeywell. Business Process Management Journal. 2001;7(2):85-99.

7. Ouwens M. Integrated care programmes for chronically ill patients: a review of systematic reviews. International Journal for Quality in Health Care. 2005Jan;17(2):141-6.

8. Lee SS. Quebec's Health System: A Decade of Change, 1967-77. Toronto, ON: The Institute of Public Administration of Canada; 1979.

9. Sommet Annuel [Internet]. Sommet Annuel FRESQue. FRESQue; 2016 [cited 2017Feb18]. Available from: http://www.lefresque.com/sommetannuel/

10. Vendeville G. Quebec Medical Students Stage Oneday Strike for Bill 20 Protest. Montreal Gazette [Internet]. Postmedia News ; 2015Mar30 [cited 2017Feb17]; Available from:

http://montrealgazette.com/news/local-news/quebecmedical-students-on-one-day-strike-to-protest-bill-20 